УДК 294.3(73)

DOI: 10.18101/1994-0866-2020-3-44-52

\title{
ОСНОВЫ БУДДИЙСКОГО МИРОВОЗЗРЕНИЯ: ЧЕТЫРЕ БЛАГОРОДНЫЕ ИСТИНЫ И НАУКА О СОСТРАДАНИИ
}

\author{
(c) Аякова Жаргал Аюшиевна \\ доктор философских наук, \\ Бурятская государственная сельскохозяйственная академия имени В. Р. Филиппова \\ Россия, 670034, г. Улан-Удэ, ул. Пушкина, 8 \\ azhargal@yandex.ru
}

\begin{abstract}
Аннотация. Будда проповедовал свое учение, которое может быть сведено к доктрине о Четырех благородных истинах, включающих в себя множество аспектов и являющихся всеобъемлющими. Когда Дхарма распространилась по всей Древней Индии, появились разные подходы к учению, приведшие к разделению сангхи на многочисленные школы, которые развивались через непрерывные линии учителей. Благодаря непревзойденным мастерам и ученым буддизм стал безграничным духовно-интеллектуальным ресурсом и практическим руководством для тренировки и трансформации ума, а сострадание (каруна) признано высшей степенью нравственности. Сам Будда утверждал, что его учение не является догматом и следует его принимать посредством проверки через собственный опыт. Тхеравада и Махаяна имеют разные подходы к изучению Четырех благородных истин и их практическому применению. Тем не менее, оставаясь центральной доктриной буддизма, Четыре благородные истины обеспечивают концептуальную основу для всей буддийской мысли. Ключевые слова: буддизм; дхарма; Четыре благородные истины (ЧБИ); сострадание; бодхисаттва; Махаяна; Тхеравада; самсара; карма.
\end{abstract}

\section{Для цитирования}

Аякова Ж. А. Основы буддийского мировоззрения: Четыре благородные истины и наука о сострадании // Вестник Бурятского государственного университета. Философия. 2020. Вып. 3. С. 44-52.

Термин «буддизм» начал употребляться многими веками позже, когда западные исследователи использовали его относительно множества традиций, возникших из учения. Это учение было настолько плодотворным, что послужило основой для создания различных школ с собственными философско-логическими построениями. Наиболее крупные направления в буддизме - Тхеравада (школа палийского канона) и Махаяна (школа санскритского канона) - на протяжении многих веков отражают внутреннюю борьбу различных тенденций, хотя они базируются, как принято считать, на общей доктрине Четырех благородных истин (ЧБИ). Школа Тхеравады полагает, что фундаментом всех ответвлений была и остается первая проповедь о ЧБИ, данная Буддой в Сарнатхе, недалеко от Бенареса (Варанаси) в Индии. Они не могут быть первой ступенью для начинающих буддистов, они сами по себе глубинное учение для постижения на протяжении всей жизни. Согласно K. Андерсон (C. Anderson), в научной среде существует тенденция представлять Четыре благородные истины как центральное учение в буддизме, который был «упрощен и сведен к учению более доступному, податливому, а значит, 
Ж. А. Аякова. Основы буддийского мировоззрения: Четыре благородные истины и наука о сострадании

легко приспособляемому для небуддистов» $[1$, с. 196]. Она полагает, что ЧБИ являются не просто незыблемым постулатом, но это положения, требующие более детального и сложного прочтения. Поэтому они исследуются в полном толковании канона Тхеравады и в более широком контексте южноазиатской литературы [1, с. 198].

Методика исследования состоит в анализе ЧБИ - философской доктрины буддийского учения с позиций традиционного и западного подходов. Сравнительный анализ подходов в презентации ЧБИ представляется весьма актуальным в контексте дискуссии глобальной буддологии. К важным направлениям этой дискуссии относятся, в частности, распространение и адаптация буддийского учения в контексте западной культуры через практическое осмысление его основных постулатов и применение их в повседневной жизни.

В Махаяне ЧБИ рассматриваются не так пристально, как ее центральные концепции шуньяты и пути бодхисаттвы. Более того, идеал бодхисаттвы создает некую напряженность в объяснении ЧБИ. С точки зрения Махаяны полностью просветленный Будда не покидает самсару, но остается в ней из сострадания ко всем живым существам. ЧБИ, нацеленные на прекращение самсары, не дают доктринальной основы для этого воззрения. Согласно J. Makransky, вопрос о том, как освобожденное существо все еще может быть «всепроникающим и действующим в этом мире», является источником «продолжающегося доктринального напряжения в отношении состояний Будды (Buddhahood) на протяжении всей истории Махаяны в Индии и Тибете» [2, c. 346-347]. Согласно Ch. Gowans, многие западные последователи настроены довольно скептически к концепциям кармы и перерождения, принципиальным для Четырех благородных истин. Здесь фундаментальные проблемы традиционного буддизма и современного западного буддизма не совпадают. Gowans продолжает, что основная моральная ориентация буддистов определяется верой в карму и перерождение, отрицание данного мировоззрения подрывает их историю, нравственную ориентацию и религиозные основы [3, c. 76-88]. Его Святейшество Далай-лама XIV утверждает, что буддисты верят в перерождение и эта вера распространена среди его последователей. Он замечает, что концепция перерождения является более сложной, чем она обычно представляется буддистам-мирянам. Здесь речь идет о непрерывном потоке сознания, идущем с прошлых жизней и продолжающемся в будущих.

Таким образом, Тхеравада и Махаяна имеют разные подходы к изучению ЧБИ и применению их на практике. Тем не менее, оставаясь центральной доктриной буддизма, ЧБИ обеспечивают концептуальную основу для всей буддийской мысли.

Первая благородная истина - страдание (dukkha) ${ }^{1}$. Жизнь как страдание рассматривается буддистами не с точки зрения трагизма или пессимизма, а определяется реалистичным подходом к центральной проблеме человеческого бытия и

\footnotetext{
1 Западные переводчики буддийских текстов используют различные термины для передачи значения палийского dukkha. Ранние переводчики (до 1970-х гг.) обычно переводили dukkha как "страдание". Более поздние переводчики подчеркивают, что "страдание" является слишком сильным словом, схожим мучению, и отмечают ограниченный перевод термина dukkha, поэтому предпочитают либо оставлять этот термин не переведенным, 
осмыслением перманентности страданий вообще в мире, окружающих нас людей и животных, а не только своих. Физические и эмоциональные проблемы относятся к страданиям очевидным, изменчивость и непостоянство вещей и явлений причиняют страдания перемен, неведение относительно природы реальности, искаженное представление о действительности обусловливает всепроникающее страдание. Dukkha выражает основное качество самсарного бытия, бесконечного круговорота рождений, старости, болезни и смерти. Радость и удовлетворение настолько кратковременны и переменчивы, что они только усугубляют страдания жизни. Всепроникающее страдание коренится в неведении и в иллюзорном восприятии самсары, а чтобы избавиться от страданий, необходимо преодолеть неведение и узреть истинную реальность. С буддийской точки зрения существа с низшими способностями стремятся к освобождению от очевидного страдания. Существа со средними способностями приходят к пониманию, что удовольствие на самом деле является страданием перемен. Существа с высшими способностями стремятся освободиться от всепроникающего страдания, преодолевая омрачения ума на пути к просветленному сознанию.

Вторая истина - причина (samudaya). Причина страданий коренится в желаниях, цепляниях, влечениях, привязанностях. Человек рождается и попадает в круговорот зависимостей и собственничества. Мы не получаем то, чего хотим, но получаем то, чего не хотим, в этом заключается корень страдания. Неведение, влечение, ненависть являются основными умственными импульсами, которые порождают остальные эмоции и чувства, служащие мотивами неблагих деяний и поступков ${ }^{1}$. Неведение кроется в том, что человек сам создает причины страдания, продолжая цепляться за самсарные удовольствия, по прошествии которых наступают разочарование, отчаяние, страх, гнев, депрессия.

Третья истина - прекращение (nirodha). Страдания могут быть прекращены, а для этого наш ум должен полностью освободиться от неведения, влечения, ненависти. Долгое время западные исследователи акцентировали свое внимание на первых двух благородных истинах, из-за чего учение приобретало безысходно пессимистический характер, противоречащий западному гуманистическому духу. Однако для буддистов самым важным является постулат о том, что страдания могут быть прекращены, поэтому необходимо достижение подлинного успокоения ума для освобождения из самсары страданий. Здесь важно узреть истинную природу реальности посредством анализа взаимозависимости всех вещей и явлений и их причинно-следственных связей.

Четвертая истина - Восьмеричный путь (magga), посредством которого Будда преподал методы прекращения страданий и достижения просветления ${ }^{2}$. Это

либо пояснять его такими переводами, как беспокойство, тревога, разочарование, неудовлетворенность (Prebish,1993; Keown, 2003).

${ }^{1}$ В буддийской иконографии три яда ума - неведение, влечение, ненависть - изображены в центре колеса самсары в виде неразрывных свиньи, петуха и змеи соответственно.

${ }^{2}$ Термин «просветление» является западным переводом палийского bodhi, глагольный корень которого означает «пробудиться». Термин был распространен через переводы M. Müller в XIX в. и стал синонимом духовной самореализации в условиях социальной 
Ж. А. Аякова. Основы буддийского мировоззрения: Четыре благородные истины и наука о сострадании

не что иное, как система образования, помогающая осознать собственную природу и обрести опыт постижения (познание пути), пробуждения (начало пути) и просветления (реализация пути). Восьмеричный путь содержит восемь принципов, объединенных в три базовые разделы: мудрость (праджня), этика (шила) и медитация (самадхи и дхьяна).

Первые два принципа Восьмеричного пути - правильное воззрение и правильное намерение - относятся к мудрости. В буддийском смысле правильное воззрение означает видение жизни относительно ЧБИ; наши действия и даже бездействие имеют сиюминутные и отдаленные последствия, смерть не есть конец, а наши мысли, идеалы, поступки и убеждения имеют кармические последствия. Правильное намерение основано на решимости освободиться не только от страданий, но и их причин, для этого необходимо избавиться от всех омрачений ума (клеш), препятствующих реализации пути.

Следующие три принципа - правильная речь, правильное действие, правильный образ жизни - относятся к этике поведения. Правильная речь несовместима с ложью (даже в малом), пустословием, грубостью, оскорблениями, сплетнями и т. п., создающими негативные условия и причины. Правильное действие означает воздержание от убийства любых живых существ (даже насекомых); взятия или отнятия того, что тебе не принадлежит, невозвращения долгов; неподобающего сексуального поведения. Правильный образ жизни определяется прежде всего честным и справедливым способом добывания средств для существования и довольствованием необходимым.

К медитации относятся правильное усердие, правильное памятование, правильная концентрация. Для правильного усердия необходима концентрация сил и возможностей для воплощения необходимых состояний (самоосознавание, спокойствие, умиротворение). Правильное памятование (сати) подразумевает внимание к телу, чувствам, мыслям и состояниям ума не только во время медитации, но и в повседневной жизни. Правильное сосредоточение означает глубокую медитацию (дхьяна), внутреннее фокусирование на состоянии ума, погруженного до степени прозрения, которую испытал Будда при медитировании. Буддийская мудрость - это признание «четырех печатей» буддизма: все явления изменчивы и непостоянны; все омрачения есть суть страданий; все явления лишены самобытия; нирвана ${ }^{1}$ - прекращение страданий.

Современные буддийские учителя адаптировали ЧБИ для прагматичной западной аудитории, интересующейся прежде всего психологическими аспектами буддизма и применением их в повседневной жизни. Например, широко известная на Западе буддийская монахиня Пема Чодрон, ученица неординарного мастера медитации Чогьям Трунгпа, одного из первых тибетских учителей, обосновавшихся

обусловленности. С буддийской точки зрения просветление (пробуждение) - полное избавление от омрачений ума (клеш), кармы и освобождение от цепи перерождений.

${ }^{1}$ Между самсарой и нирваной существует мнимая граница для и внутри конкретного отдельного живого существа и лишь до тех пор, пока оно «остается в самсаре». Нирвана букв.: «прекращение», «исчезновение»; устранение страдания, безусловное состояние, освобождение от закона кармы. Считается, что нирвану невозможно описать, объяснить, адекватно выразить словами, поскольку она вне логики, вне времени. 
в США, объясняет Четыре благородные истины относительно непостоянства мыслей и эмоций, причиняющих страдания человеческому эго. Пема Чодрон - одна из первых женщин Запада, принявшая монашество в буддизме и ставшая полнопосвященной бхикшуни, является автором многочисленных трудов по буддизму, адресованных широкому кругу читателей и посвященных повседневным проблемам человека. Ее книги отличаются доступностью и применимостью к жизни любого, даже далекого от буддийских практик человека. Стоит отметить, что западные учителя, объясняя философию буддизма, стараются не использовать сложные термины и избегают риторику наставлений и нравоучений, а представляют мировоззрение в доступной и популярной форме с использованием художественных приемов и образов.

Первая благородная истина гласит, что человеку свойственно чувствовать дискомфорт. Ничто по своей сути не может быть так или иначе. Вокруг нас ветер, огонь, земля, вода всегда изменчивы, приобретают разные формы и качества, словно магические явления. Мы также изменчивы, как погодные условия. Мы отливаем и прибываем, как приливы, растем и убываем, как луна. Мы не видим, что, как и погода, мы изменчивы, а не постоянны. И поэтому мы страдаем.

Вторая благородная истина гласит, что наше внутреннее сопротивление это основной механизм действия того, что мы называем эго, это сопротивление жизни вызывает страдание. Традиционно говоря, причина страданий связана с нашим узким видением, то есть мы зависимы от собственного Я. Мы сопротивляемся тому, что мы изменчивы и непостоянны, что у нас та же энергия, как и у всех живых существ. Когда мы сопротивляемся и упираемся изо всех сил, мы пытаемся стоять на своем как неизменном. Сопротивление - это и есть наше эго.

Третья благородная истина гласит, что страдания прекращаются, когда мы отпускаем попытки поддерживать свое огромное Я любой ценой. Это то, что мы практикуем в медитации. Когда мы отпускаем мысли и события, мы просто сидим с качеством и энергией той конкретной «погоды», которой мы пытались сопротивляться.

Суть четвертой благородной истины заключается в том, что в нас заложено все для осознания того, что мы являемся частью энергии, которая создает все. Нам следует научиться сидеть неподвижно, как гора во время урагана, не прикрываясь от истины, естественности и непосредственности, просто быть частью жизни, понимать, что не являемся отдельным существом, которому нужно, чтобы все было по нему. Когда мы перестаем сопротивляться и позволяем погодным условиям просто пройти через нас, мы можем прожить нашу жизнь во всей ее полноте. Это зависит от нас $[4$, с. 51$]$.

Западные ученые признают, что современные психологические теории явно ограничены рамками западной науки и культуры, поэтому следует обратить внимание на буддийские психологические системы, созданные более двух тысячелетий назад. Проблема в том, что буддийской традиции никогда не было свойственно разделение объекта и субъекта, столь характерное для западной мысли. Психологические проблемы приобретают угрожающие масштабы, становясь причинами различных заболеваний тела и ума. Размышления над ЧБИ также призваны облегчить телесные и душевные страдания. Психологические аспекты буд- 

сострадании

дизма являются одновременно теоретическими и прикладными, на их основе разрабатываются практические методики для решения проблем в области медицины, образования, социальной поддержки. Основным отличием буддизма Махаяны является достижение освобождения не для себя, а для других, для всех живых существ, которым нужно помочь преодолеть умственные омрачения и достичь освобождения и просветления. Поэтому Будды не уходят в нирвану, а из сострадания остаются в самсаре «рассеивать тьму». Практика сострадания является фундаментальной идеей Махаяны, а ее идеалом выступают бодхисаттвы - просветленные существа, которым суждено стать буддами, но они отложили это конечное состояние, чтобы помочь другим. Согласно Махаяне, чтобы помочь, необходимо обладать наивысшим духовным качеством - бодхичиттой, т. е. просветленным сознанием, наполненным безграничным состраданием ко всем живым существам и желанием избавить всех от страданий круговорота бесконечных рождений. Американский философ и буддолог Кен Уилбер объясняет, что существуют относительное и абсолютное просветление. Сострадание - это относительное просветление, а пустота есть абсолютное просветление. Все, что не относится к состраданию как относительному просветлению, является «омраченным состраданием» (blind compassion), позицией, хоть и продиктованной благими намерениями, но внутренне глубоко противоречивой. Лицемерное сострадание идет на поводу эго, неважно, эго сострадающего или эго объекта сострадания, и выражается примерно так: «пожалуйста, будьте милы с моим эго». Но эго есть злейший враг, и всякий, кто с ним мил, вовсе не проявляет сострадания. Просветленное сострадание выглядит не так «мило», более того, оно может иметь угрожающий вид, так как в буддийском пантеоне просветленных существ представлены их гневные формы проявления, сметающие все, что мешает на пути истинного сострадания. Омраченное сострадание ничему и никому не угрожает, поэтому оно так популярно в среде мирян. Для практики сострадания необходимы осознанность, анализ и мудрость суждения, основанные на ценностях и глубине. Отсутствие суждений в буддизме означает беспристрастное осознание в абсолютной бодхичитте, или пустоте, а относительная бодхичитта предполагает качественные суждения на основе глубокого анализа. Уилбер считает, что омраченное сострадание почти разрушило такой подход и сделало подлинное духовное развитие очень трудным. Таким образом, подлинное духовное развитие или пробуждение возможно при реализации пути бодхисаттвы и достижения бодхичитты [5].

Безусловно, сострадание, как и другие эмпатические характеристики, является естественным образом присущим человеку качеством. Но в Махаяне речь идет о сострадании как главной духовной установке и особой практике, а не просто человеческом чувстве. «Великое сострадание, в отличие от того естественного чувства сострадания, которое есть у всех людей, если речь не идет о патологии, сочетается с мудростью постижения бессамостности. Оно не присутствует в уме естественным образом, а взращивается с помощью специальных методов, объясняемых в учении Махаяны» [6, с. 296].

Буддийское сострадание - это прежде всего безусловное сострадание. Оно не может быть направлено лишь на близких и любимых людей и быть биологически обусловленным и пристрастно ограниченным. Для развития безусловного сострадания требуются тонкость и проницательность ума, прочного в парамитах 
щедрости, самоконтроля, бдительности, терпения, медитации, мудрости. Чувство сострадания изначально заложено в человеческой природе и должно развиваться на глубоком понимании природы реальности, ее изменчивости и непостоянстве. Западные ученые, изучая природу сострадания, пришли к выводу, что практика сострадания наряду с совершенствованием личности ослабляет ложное чувство собственного независимого существования. Американский физик В. Мэнсфилд, изучая природу сострадания, проводит параллели между обменивающимися свойствами частиц в квантовой механике и перенесением «Я» на место другого человека. Ничто не существует так, как мы это видим или представляем; восприятие реальности - это процесс, в котором непосредственно участвует наше сознание. Такая медитация ослабляет привязанность к собственному «Я» и помогает произвести обмен этим «Я» с другим. Он приходит к выводу, что медитация на сострадание наряду с совершенствованием личности ослабляет ложное чувство собственного независимого существования, в котором коренится страдание. Ссылаясь на буддийских учителей, он говорит, что самовлюбленность, непрерывная забота о своем эго и его желаниях на самом деле является труднейшим препятствием на пути к счастью, тогда как любовь и забота о других являются величайшими источниками радости и удовлетворения [7, с. 208].

Теоретики, начиная с Дарвина, утверждали, что переживания горя при виде чьих-либо боли или страданий мотивируют сострадательные действия. Дарвин писал: «Мы стремимся облегчить страдания другого человека, чтобы при этом могли уменьшиться наши собственные болезненные чувства». Маловероятно, что на взгляды Дарвина повлияли буддийские представления, однако они удивительно схожи. Эмпатическое беспокойство может играть меньшую роль и быть не таким сильным при отдаленном сострадании, как при непосредственном сострадании. При отдаленном сострадании человек также может менее интенсивно переживать то, что Экман называет радостью сострадания [8]. Возможно, что радость сострадания есть косвенный результат способности поддерживать уважение к себе за добродетельные поступки. Экман допускает, что у каждого человека в базе данных эмоциональной готовности есть «глобальное сострадание», но его необходимо пробудить. Это может произойти под влиянием, например, общенациональной трагедии, такой как теракт в Нью-Йорке 11 сентября 2001 года. Предполагается, что все люди обладают глубинным сострадательным потенциалом, но у большинства он должен быть активирован. Гипотеза состоит в том, что сострадание имеет биологическую основу, а значит, потенциал есть у всех и он может раскрыться.

Все традиции буддийского учения в настоящее время процветают на Западе, хотя они почти не соприкасаются друг с другом из-за этнической и культурной обособленности, а также все больше разделяющейся пропастью между буддийскими новообращенными и азиатскими иммигрантами. Однако многие западные буддисты надеются, что присутствие многообразия традиций обеспечит большее взаимопонимание и приведет к созданию новых форм буддизма, отвечающих нуждам и интересам современного общества. Они считают, чем глубже мудрость, выходящая за пределы привычных представлений и субстанционализирующих онтологий, тем больше ум становится сострадательным. Буддийские принципы все 

сострадании

больше входят в сферу делового общения и становятся практическим руководством для успешной работы и достижения личных и профессиональных целей. Учитель тибетского буддизма и успешный бизнесмен M. Roach в своей книге «Кармический менеджмент» переворачивает традиционную деловую ментальность заявлением о том, что помощь другим достигать целей и становиться успешным - поставщикам, клиентам или конкурентам - является ключом к успеху, как в жизни, так и в бизнесе. Опираясь на собственный предпринимательский опыт, автор объясняет, как возможно, используя буддийские принципы, достичь целей в бизнесе. Каждый этап в «Кармическом менеджменте» начинается с изложения буддийского воззрения и объясняется, как это относится к жизни и работе в XXI веке. «Постройте несокрушимую стратегию роста бизнеса на помощи другим людям и своим конкурентам», - так звучит идея сострадания в сфере бизнеса, провозглашенная М. Роуч [9]. Кармический подход в работе и жизни - это эффект бумеранга: что посеешь, то и пожнешь, а глобальное сострадание заложено в деталях, эмоциях, поступках. Поддержка коллег и сорадование их успехам рано или поздно приведут к тому, что вы почувствуете такое же отношение к себе. Надо отметить, что «Кармический менеджмент» не для всех: те, кто интересуются бизнесом, но отвергают нематериальный мир, не смогут принять ее.

Будда из великого сострадания открыл Четыре благородные истины и предложил широкий путь сострадательной практики, доступный для всех людей. Главный практический смысл доктрины буддийского учения заключается в том, что ее постижение помогает освободиться от всех цепляний и деяний, в особенности от пут эгоцентризма и себялюбия, которые вместе с неведением воспроизводят механизм сансары. Человек, понявший это, освобождается от ложных концептов, пронизывающих нашу жизнь, и всех ее предрассудков, страстей, борьбы и приходит к кардинальной перестройке системы отношения к себе и взаимодействия с другими. Очевидно, что буддизм как нравственное учение востребовано современным обществом, а значит, его безграничный духовно-интеллектуальный потенциал будет развиваться и открываться всему миру.

Лumepamypa

1. Anderson C. Pain and Its Ending: The Four Noble Truths in the Theravada Buddhist Canon, Motilall Banarsidas, 2001. 270 p.

2. Makransky John J. Buddhahood Embodied: Sources of Controversy in India and Tibet. SUNY, 1997. 524 p. $344 \mathrm{p}$.

3. Gowans, Christopher W. Buddhist Moral Philosophy: An Introduction, Routledge, 2014.

4. Pema Chodron. The Wisdom of No Escape. Shambhala Classics, 2001. 120 p.

5. Кен Уилбер. O настоящем сострадании [Электронный pecypc]. URL: https://meditation-portal.com/ken-uilber-o-nastoyashhem-sostradanii/ (дата обращения: 27.03.2020).

6. Урбанаева И. С. Буддийская философия и медитация в компаративистском контексте на основе индо-тибетских текстов и живой традиции тибетского буддизма. УланУдэ: Изд-во ИМБТ СО РАН, 2014. 375 с.

7. Мэнсфилд В. Квантовая механика и сострадание [Электронный ресурc]. URL: http://savetibet.ru/2010/10/17/quantum_physics_and_compassion.html (дата обращения: 15.03.2017). 
8. Экман П. Психология сострадания. СПб.: Питер, 2017. С. 39.

9. Роуч M. Бизнес - не только деньги [Электронный pecypc]. URL: http://cityclass.ru/roach_money/?event=13401 (дата обращения: 23.03.2020).

Статья поступила в редакиию 22.09.2020; одобрена после рецензирования 22.09.2020; принята к публикации 28.09.2020.

\section{BASIC BUDDHISM: THE FOUR NOBLE TRUTHS AND THE SCIENCE OF COMPASSION}

\section{Zhargal A. Ayakova}

Dr. Sci. (Philos.),

Filippov Buryat State Agricultural Academy

8 Pushkina St., Ulan-Ude 670034, Russia

azhargal@yandex.ru

Abstract. The Buddha apprehended the Four Noble Truths which are traditionally identified as the first teaching and considered as one of the most important teachings in Buddhism. Buddha's teachings were propagated by his followers, and these lead to the development of many sub-schools of Buddhist thought based on different interpretations and authentic teachings of the Buddha. The best known and most widespread in the modern era traditions are Theravada and Mahayana. Compassion (karuna) is considered as an important quality in all schools of Buddhism, but in Mahayana tradition compassion is the highest quality to be cultivated on the bodhisattva path. The Buddha argued that his teaching is not a dogma and should be accepted through one's own experience. Different Buddhist schools have various approaches to the study and practice of the Four Noble Truths. Nonetheless while remaining the central doctrine of Buddhism the Four Noble Truths provide a conceptual foundation for all Buddhist thought.

Keywords: Buddhism; Dharma, the Four Noble Truths; compassion; Mahayana, Theravada; bodhisattva; saṃsāra; karma. 